\title{
Shielding Effect of Boron Carbide Aluminium Metal Matrix Composite against Gamma and Neutron Radiation
}

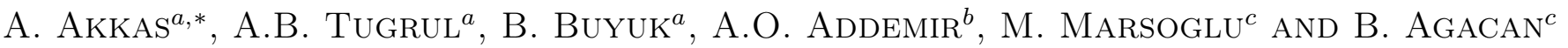 \\ ${ }^{a}$ Istanbul Technical University, Energy Institute, Nuclear Researches Division, Istanbul, Turkey \\ ${ }^{b}$ Istanbul Technical University, Chemistry and Metallurgical Faculty, Materials Science Div., Istanbul, Turkey \\ ${ }^{c}$ Ylldiz Technical University, Materials Science and Engineering Faculty, Istanbul, Turkey
}

\begin{abstract}
In this study, boralyn (boron carbide-aluminum metal matrix composite material - $\mathrm{Al} / \mathrm{B}_{4} \mathrm{C}$ ) composite materials were investigated on shielding effect against gamma and neutron radiations. The samples were prepared as $5 \mathrm{wt} \%, 10 \mathrm{wt} \%, 15 \mathrm{wt} \%$, and $20 \mathrm{wt} \%$ reinforcement content and for each content of material has composed in five different average particle sized $(3 \mu \mathrm{m}, 53 \mu \mathrm{m}, 113 \mu \mathrm{m}, 200 \mu \mathrm{m}$, and $500 \mu \mathrm{m})$. Linear and mass attenuation coefficients were calculated experimentally for each composite material against Cs-137 gamma source. Theoretical mass attenuation coefficients of material were calculated by using XCOM computer code. Then the theoretical results were compared with experimental results. Then, macroscopic cross-section values were calculated experimentally for each composite material against $\mathrm{Pu}-\mathrm{Be}$ neutron source. As the conclusion of the study, it could be understood that in spite of decrease of the attenuation coefficient against gamma radiation, the adding materials give rise to increase the shielding ability of material against neutron radiation.
\end{abstract}

DOI: 10.12693/APhysPolA.128.B-176

PACS: 25.20.Dc

\section{Introduction}

Radiation shielding involves at placing a shielding material between the ionizing radiations source and the worker or the environment [1]. There are several factors that influence the selection and use of radioactive shielding materials. Considerations such as attenuation effectiveness, strength, resistance to damage, thermal properties, and cost efficiency can affect radiation protection in various ways [2].

Boron carbide $\left(\mathrm{B}_{4} \mathrm{C}\right)$ is a very hard $(9.5+$ in Mohs scale), low specific gravity (2.52), covalent ceramic that offers distinct advantages for applications involving neutron absorption, wear resistance and impact resistance. The extreme sensitivity of $\mathrm{B}_{4} \mathrm{C}$ to brittle fracture $\left(K_{l c}=\right.$ $3.7 \mathrm{MPa} \mathrm{m}{ }^{1 / 2}$ ) and the difficulties associated with fabricating fully dense microstructures are serious limitations [3-6]. By using certain additive, it is more suitable for production or manufacturing of them.

Aluminium alloys are still the subjects of intense studies, as their low density gives additional advantages in several applications. These alloys have started to replace cast iron and bronze to manufacture wear resistance parts [7]. Aluminum reinforced boron carbide composite gives interesting features such as high strength and high hardness $[8,9]$. These characteristics have made this composite as a very potential material in engineering field. The usage of aluminum reinforced with boron carbide composite becomes especially in neutron application due to its ability to absorb neutron very well.

*corresponding author; e-mail: akkasayhan@hotmail.com
Boron carbide is a material having a higher strength than aluminum with the reading of 2.75 Mohs compared to 9.3 Mohs. Thus, the increase in the quantity of boron carbide in the composites increases the strength of the $\mathrm{Al} / \mathrm{B}_{4} \mathrm{C}$ composites [10].

In this study, the shielding effect of boralyn against gamma and neutron radiations were investigated.

\section{Materials and methods}

Gamma ray transmission technique based on measuring the attenuation photons of an incident radiation beam which are absorbed when pass across the materials. NaI scintillation detector was used for detection of gamma photons of Cs-137 source [11]. Materials were placed between source and detector. Attenuation coefficient is determined for a given material by interposing increasing thickness of materials. Special precautions are taken to reduce scattered radiations by using collimators. $\mathrm{Pu}-\mathrm{Be}$ neutron source in howitzer was used for neutron experiments with paraffin collimators.

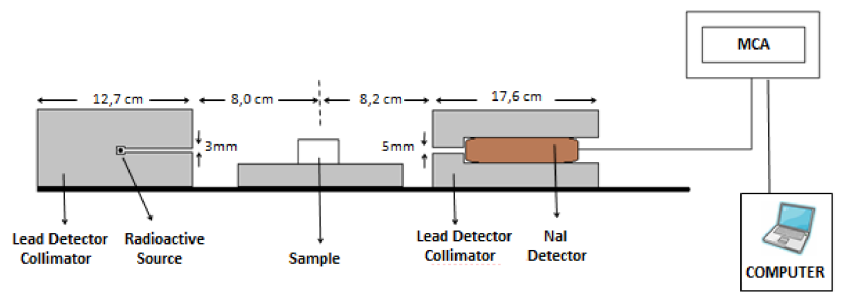

Fig. 1. Schematic view of gamma setup.

The Beer law establishes the relationship between the attenuated radiation intensity. It can be written as 
$I=I_{0} \exp (-\mu x)$, where $I_{0}$ is incident gamma ray beam intensity. It is emergent gamma ray beam intensity (count/s), $\mu$ is the linear attenuation coefficient of the sample and $x$ is the thickness of the sample $(\mathrm{cm})[12]$. The mass attenuation coefficient $\mu_{m}$ can be written as $\mu_{m}=\mu / \rho$ where $\mu$ is the mass attenuation coefficient and $\rho$ is the density of the sample. Figure 1 shows gamma setup schematically.

The attenuation relationship for aluminium-boron carbide composite against neutron radiation can be expressed as $I=I_{0} \mathrm{e}^{-N \sigma a x}$ where $I_{0}$ and $I$ are intensities of incoming and outgoing neutrons flux, $N$ is the atomic nuclear number per cubic centimetres, $x$ is the thickness of the absorber and $\sigma_{\mathrm{a}}$ is the neutron absorbing crosssection [13]. Figure 2 shows neutron setup schematically.

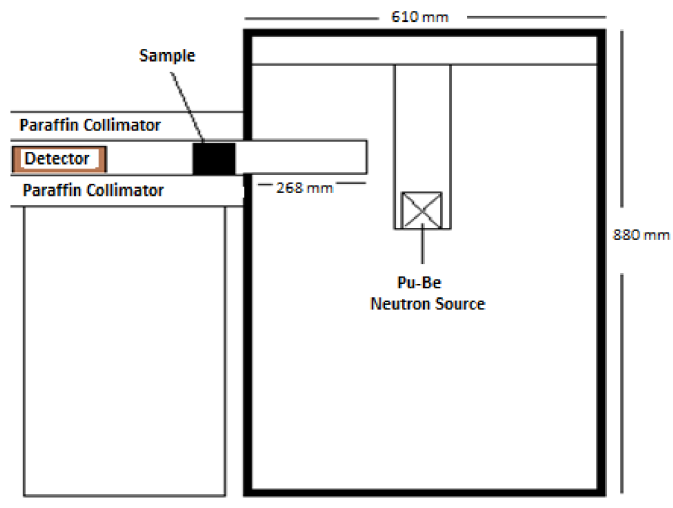

Fig. 2. Schematic view of neutron setup.
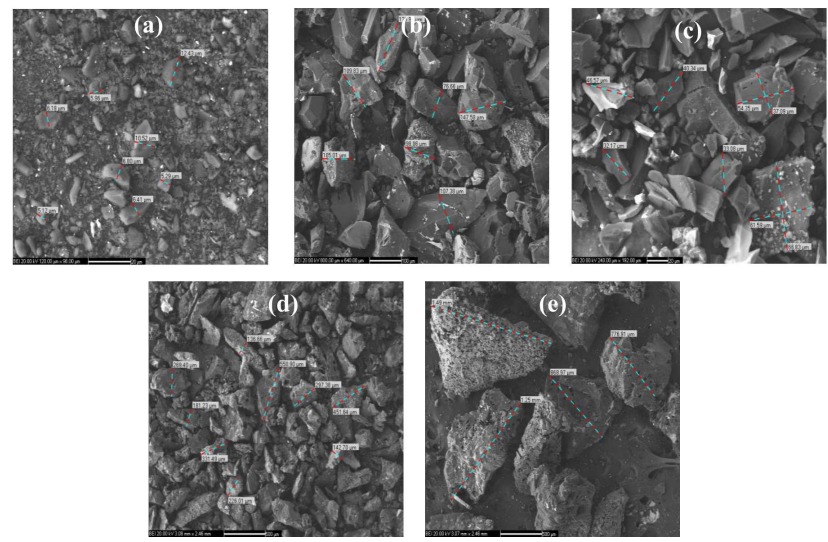

Fig. 3. SEM views of composite materials which have different average boron carbide particle size: (a) $3 \mu \mathrm{m}$ $(\times 1000)$, (b) $53 \mu \mathrm{m}(\times 500), \quad(\mathrm{c}) 113 \mu \mathrm{m}(\times 150)$, (d) $200 \mu \mathrm{m}(\times 39)$ and (e) $500 \mu \mathrm{m}(\times 39)$.

Aluminium-boron carbide metal matrix composite materials were tested as radiation shielding material against gamma and neutron radiation. Composite materials were used in experiments produced by cold pressing method at $540{ }^{\circ} \mathrm{C}$ under 200 bar pressure for $3 \mathrm{~min}$. Composite materials have four different boron carbide content
$(5,10,15$, and $20 \mathrm{wt} \%)$ and each content of composite material have five different boron carbide average particle size $(3,53,113,200$, and $500 \mu \mathrm{m})[14]$. The scanning electron microscope (SEM) views of materials are shown in Fig. 3.

From the SEM views of materials, there can be observed homogeneous distribution of $\mathrm{B}_{4} \mathrm{C}$ particle in composite materials.

\section{The experimental results}

The graphs of relative intensity-material thickness for the composite materials against Cs-137 radioisotope were plotted in Fig. 4.

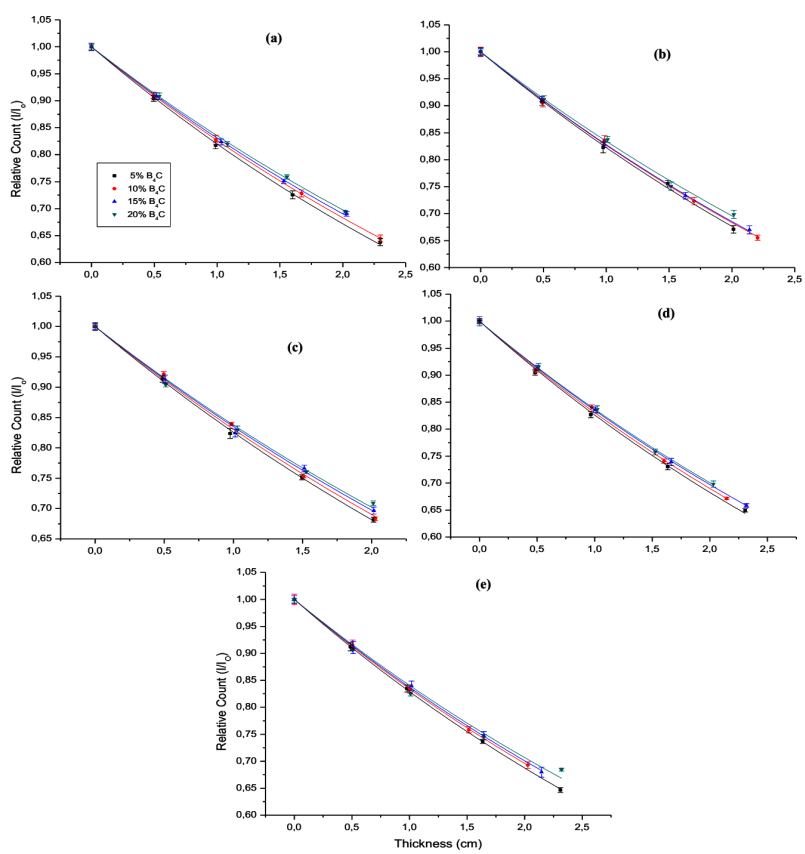

Fig. 4. Relative intensity-thickness graphs with different boron carbide average particle size against Cs137 gamma source for particle size as (a) $3 \mu \mathrm{m}$, (b) $53 \mu \mathrm{m}$, (c) $113 \mu \mathrm{m}$, (d) $200 \mu \mathrm{m}$, and (e) $500 \mu \mathrm{m}$.

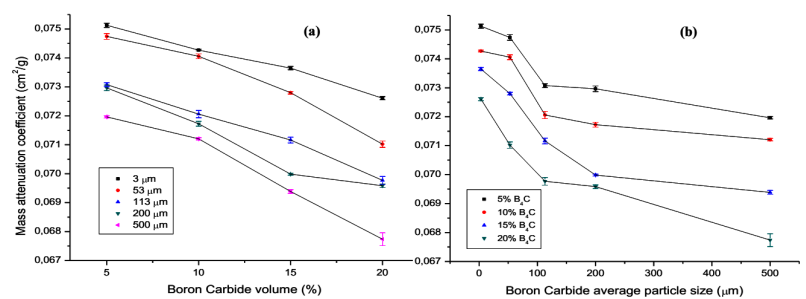

Fig. 5. (a) Boron carbide content versus gamma attenuation coefficient. (b) Boron carbide particle sized versus gamma attenuation coefficient.

From Fig. 4, the linear attenuation values were increased with increase of boron carbide reinforcing ratio 
TABLE I

Experimental and theoretical values of mass attenuation coefficients.

\begin{tabular}{c|c|c|c|c}
\hline \hline \multirow{2}{*}{$\begin{array}{c}\text { Boron carbide } \\
\text { average particle }\end{array}$} & \multirow{2}{*}{$\begin{array}{c}\text { Boron } \\
\text { carbide }\end{array}$} & \multicolumn{3}{|c}{$\mu / \rho\left[10^{-2} \mathrm{~cm}^{2} / \mathrm{g}\right]$} \\
\cline { 3 - 5 } size $[\mu \mathrm{m}]$ & {$[$ vol.\%] } & exp. & theor. & diff. \\
& & XCOM $)$ & {$[\%]$} \\
\hline \multirow{5}{*}{3} & 5 & $7.513 \pm 0.07$ & 7.456 & 0.8 \\
& 10 & $7.427 \pm 0.03$ & 7.446 & 0.3 \\
& 15 & $7.365 \pm 0.06$ & 7.436 & 1.0 \\
& 20 & $7.261 \pm 0.05$ & 7.426 & 2.2 \\
\hline \multirow{5}{*}{53} & 5 & $7.474 \pm 0.010$ & 7.456 & 0.2 \\
& 10 & $7.406 \pm 0.009$ & 7.446 & 0.5 \\
& 15 & $7.280 \pm 0.005$ & 7.436 & 2.1 \\
& 20 & $7.102 \pm 0.011$ & 7.426 & 4.4 \\
\hline \multirow{5}{*}{200} & 5 & $7.308 \pm 0.007$ & 7.456 & 2.0 \\
& 10 & $7.206 \pm 0.012$ & 7.446 & 3.2 \\
& 15 & $7.116 \pm 0.010$ & 7.436 & 4.3 \\
& 20 & $6.977 \pm 0.013$ & 7.426 & 6.0 \\
\hline \multirow{5}{*}{500} & 5 & $7.297 \pm 0.010$ & 7.456 & 2.1 \\
& 10 & $7.173 \pm 0.009$ & 7.446 & 3.7 \\
& 15 & $6.998 \pm 0.004$ & 7.436 & 5.9 \\
& 20 & $6.958 \pm 0.006$ & 7.426 & 6.3 \\
\hline & 5 & $7.196 \pm 0.004$ & 7.456 & 3.5 \\
& 10 & $7.121 \pm 0.004$ & 7.446 & 4.4 \\
& 15 & $6.938 \pm 0.006$ & 7.436 & 6.7 \\
& 20 & $6.774 \pm 0.022$ & 7.426 & 8.8 \\
& & & &
\end{tabular}

TABLE II

Experimental values of macroscopic cross-section values.

\begin{tabular}{c|c|c}
\hline \hline $\begin{array}{c}\text { Boron carbide average } \\
\text { particle size }[\mu \mathrm{m}]\end{array}$ & $\begin{array}{c}\text { Boron carbide } \\
{[\text { vol.\%] }}\end{array}$ & $\begin{array}{c}\text { Macroscopic cross- } \\
\text { section } \Sigma\left[\mathrm{cm}^{-1}\right]\end{array}$ \\
\hline \multirow{3}{*}{3} & 5 & $0.292 \pm 0.002$ \\
& 10 & $0.341 \pm 0.002$ \\
15 & $0.388 \pm 0.005$ \\
53 & 20 & $0.439 \pm 0.003$ \\
\hline \multirow{5}{*}{113} & 5 & $0.323 \pm 0.003$ \\
& 10 & $0.396 \pm 0.001$ \\
& 15 & $0.458 \pm 0.004$ \\
& 20 & $0.531 \pm 0.003$ \\
\hline \multirow{5}{*}{200} & 5 & $0.304 \pm 0.006$ \\
& 10 & $0.381 \pm 0.000$ \\
& 15 & $0.403 \pm 0.002$ \\
& 20 & $0.460 \pm 0.007$ \\
\hline \multirow{5}{*}{500} & 5 & $0.349 \pm 0.004$ \\
& 10 & $0.410 \pm 0.005$ \\
& 15 & $0.453 \pm 0.002$ \\
& 20 & $0.510 \pm 0.005$ \\
\hline & 5 & $0.335 \pm 0.000$ \\
& 10 & $0.384 \pm 0.002$ \\
& 15 & $0.459 \pm 0.001$ \\
& 20 & $0.517 \pm 0.001$
\end{tabular}

in the aluminum-boron carbide composites. The experimental mass attenuation coefficients $(\mu / \rho)$ were calculated for all boron carbide reinforced boron carbidealuminum composites from the graphs by Origin 8 computer program. On the other hand, the theoretical mass attenuation coefficients were calculated from XCOM computer code [15]. The difference percentages between theoretical and experimental values were calculated. Experimental, theoretical mass attenuation coefficients and their difference percentages were given in Table I.

From Fig. 5a, mass attenuation coefficient decreased with the increase the boron carbide ratio in the composition for our prepared samples. Effect of boron carbide average particle size on gamma ray shielding was also investigated. In addition, decreasing average boron carbide particle size caused higher linear and mass attenuation coefficients (Fig. 5b).

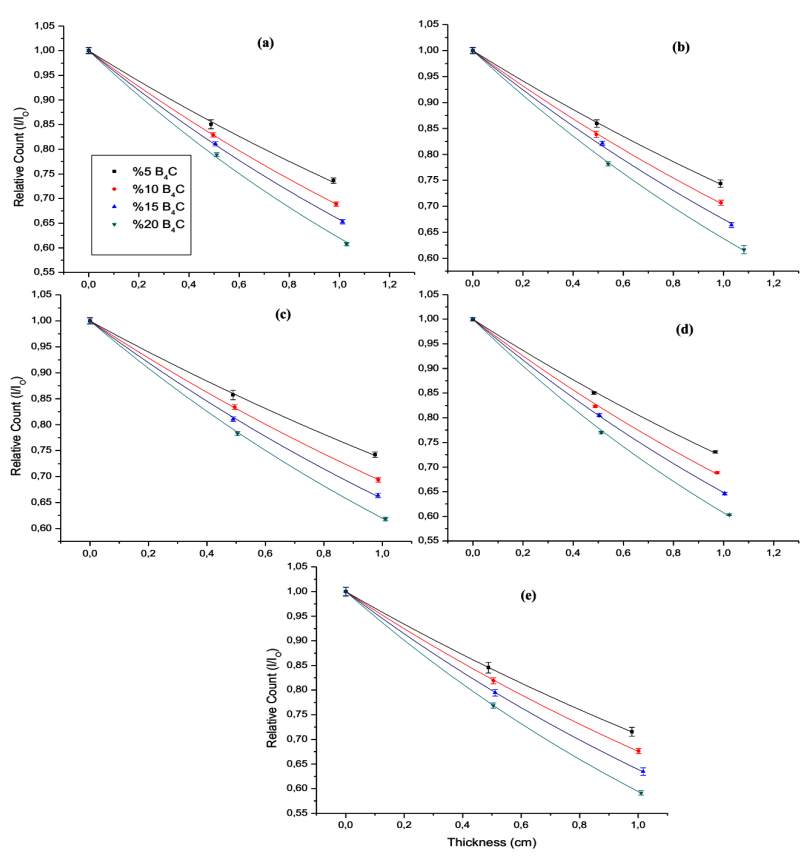

Fig. 6. Macroscopic cross-section value versus material thickness as boron carbide particle size, (a) $3 \mu \mathrm{m}$ particle size, (b) $53 \mu \mathrm{m}$ particle size, (c) $113 \mu \mathrm{m}$ particle size, (d) $200 \mu \mathrm{m}$ particle size, and (e) $500 \mu \mathrm{m}$ particle size.
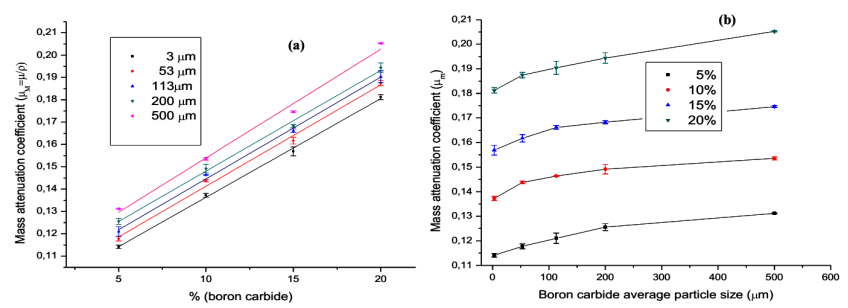

Fig. 7. (a) Macroscopic cross-section value versus boron carbide content composite material. (b) Macroscopic cross-section versus boron carbide average particle size. 
In case of neutron attenuation, thermal neutron removal cross-sections of the composites were investigated. In Fig. 6, the relative intensity-material thickness for composite materials graphs were plotted. Experimental macroscopic cross-section values were given in Table II. Macroscopic cross-section values decreased with the increase of the boron carbide ratio in the composition (Fig. 7a). In addition, decrease of average boron carbide particle size caused higher macroscopic cross-section values (Fig. 7b).

\section{Conclusion}

The linear and mass attenuation coefficients were carried out for composites by using transmission techniques. The effects of boron carbide percentage in material and size of boron carbide particles on gamma and neutron attenuation property were determined. It is concluded that increase of the boron carbide reinforcing ratio in the boralyn composites causes higher linear attenuation coefficients. Furthermore, decrease of the boron carbide particle size causes higher linear and mass gamma attenuation coefficients of the materials against Cs-137 gamma radioisotope source. Increase of the boron carbide reinforcing ratio in the boralyn composites causes higher macroscopic neutron cross-section values. Besides that, increase of average boron carbide particle size causes higher macroscopic cross-section of the boralyn material against $\mathrm{Pu}-\mathrm{Be}$ neutron source.

\section{References}

[1] Y. Elmahroug, B. Tellili, C. Souga, Int. J. Phys. Res. 3, 33 (2013).

[2] H. Hu, Q. Wang, J. Qin, IEEE Trans. Nucl. Sci. $\mathbf{5 5}, 2376$ (2008).

[3] D.C. Halverson, A.J. Pyzik, İ.A. Aksay, W.E. Snowden, J. Am. Ceram. Soc. 72, 775 (1989).
[4] U.B. Gopal Krishna, K.V. Sreenıvas Rao, B. Vasudeva, Int. J. Metall. Mater. Sci. Eng. (IJMMSE) 3, 41 (2013).

[5] G.L. Krishna, R. Sreenıvas, B. Vasudeva, Int. J. Metall. Mater. Sci. Eng. 3, 41 (2013).

[6] Y. Abdullah, M.R. Yusof, A. Muhammad, N. Kamarudin, W.S. Paulus, R. Shamsudin, N.H. Shudin, N.M. Zali, J. Nucl. Relat. Technol. 9, 42 (2012).

[7] B. Buyuk, A.B. Tugrul, A.C. Akarsu, A.O. Addemir, Acta Phys. Pol. A 121, 135 (2012).

[8] B. Buyuk, A.B. Tugrul, A.C. Akarsu, A.O. Addemir, J. Nano-Electron. Phys. 4, 4 (2012).

[9] B. Buyuk, A.B. Tugrul, S. Aktop, A.O. Addemir, Acta Phys. Pol. A 123, 177 (2013).

[10] P. Zhang, Y. Li, W. Wang, Z. Gao, B. Wang, J. Nucl. Mater. 437, 350 (2013).

[11] B. Buyuk, A.B. Tugrul, Radiat. Phys. Chem. 97, 354 (2014).

[12] A. Akkas, Ph.D. Thesis, Energy Institute, Istanbul Technical University (it is continued).

[13] A. Kurtoğlu, A.B. Tuğrul, Appl. Radiat. Isot. 58, 5 (2003).

[14] B. Ağacan, M. Marşoğlu, M.Sc. Thesis, Yildiz Technical University, Metallurgical Engineering, Yildiz 2013, p. 57.

[15] M.J. Berger, J.H. Hubbell, S.M. Seltzer, J. Chang, J.S. Coursey, R. Sukumar, D.S. Zucker, K. Olsen, XCOM: Photon Cross-Section Database, http:// www.nist.gov/pml/data/xcom/index.cfm, U.S. (accessed 20 Sept. 2012). 